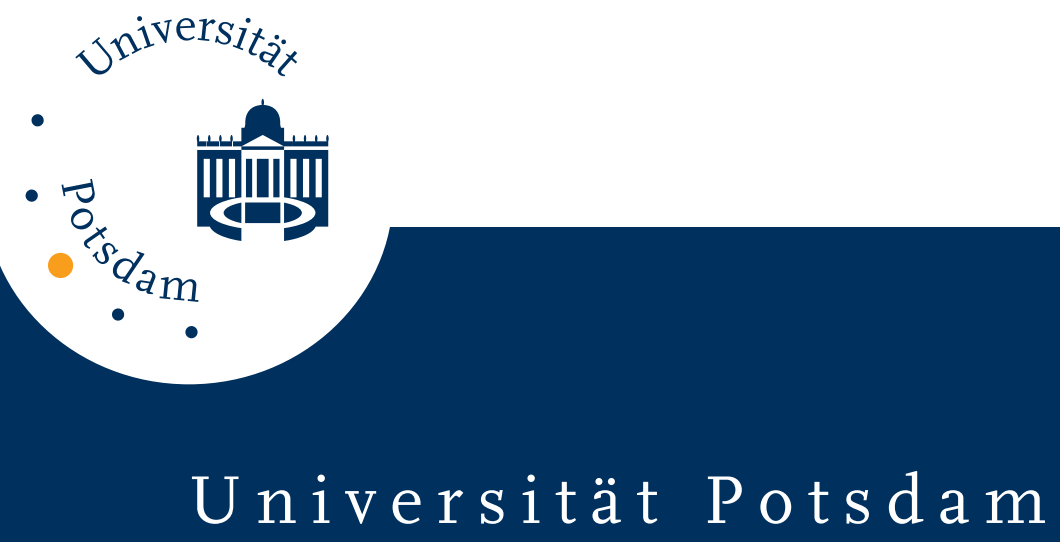

Bernd Six, Barbara Krahé

\title{
Implicit psychologists' estimates of attitude-behaviour consistencies
}

first published in:

European Journal of Social Psychology, 14 (1984) Issue 1, p. 79-86, DOI: 10.1002/ejsp.2420140107

Postprint published at the Institutional Repository of Potsdam University: In: Postprints der Universität Potsdam

Humanwissenschaftliche Reihe ; 78

http://opus.kobv.de/ubp/volltexte/2009/3442/

http://nbn-resolving.de/urn:nbn:de:kobv:517-opus-34427

Postprints der Universität Potsdam

Humanwissenschaftliche Reihe ; 78 


\title{
Implicit psychologists' estimates of attitude-behaviour consistencies
}

\author{
BERND SIX and BARBARA KRAHÉ \\ Erziehungswissenschaftliche Hochschule, \\ Rheinland-Pfalz, Abteilung Landau, \\ Im Fort 7, D-6740 Landau, West Germany
}

\begin{abstract}
To investigate the relationship between implicit psychological hypotheses and explicit empirical findings, summaries of twenty published studies on attitude-behaviour consistency were presented to a sample of forty-eight psychology undergraduates. Subjects were asked to estimate the percentage of agreement between attitudes and behaviour obtained by each study. Correlations between subjects' covariation judgements and empirically obtained attitude-behaviour consistencies were minimal and nonsignificant. Results are discussed in the light of more recent research on attitudebehaviour relationship.
\end{abstract}

\section{INTRODUCTION}

Intuitive or commonsense psychological theories are becoming increasingly popular as challenges and touchstones of scientific psychological reasoning (Schneewind, 1982; Semin, Rosch, Krolage and Chassein, 1981; Wish and Kaplan, 1977). Stated in terms of Wegner and Vallacher's conception of implicit psychology, 'psychological theory and research is an extension of concerns held by the average individual' (Wegner and Vallacher, 1977, $c f$. also Furnham and Henderson, 1983).

In a study allowing direct comparisons between implicit and explicit personality theories, Semin et al. (1981) investigated whether naive judges are able to reproduce the scale structures of scientific personality inventories. Subjects were presented the scale labels of two widely used personality inventories and were then asked to categorize the complete item pool under these labels. The results show that naive subjects not only correctly identify the items belonging to each of the scales but also reproduce the interscale correlational structure of the inventories. From their findings, the authors conclude that scientific or explicit theories of personality as well as their corresponding measurement devices may be conceived of as derivations and explications of generally accepted commonsense definitions of personality concepts.

Given this close relation between 'implicit' and 'explicit' formulations of psychological theories, any attempt at scientific analysis is confronted with the 
claim to be able to produce non-trivial, i.e. noncommonsensical results (Sjöberg, 1982a,b; Smedslund, 1982). This challenge is particularly relevant to the field of social psychology because its emphasis lies on the analysis and explanation of everyday social experience. The contribution of social psychological research should go beyond providing significance tests for well-established intuitive evidence to counter the layman's verdict that 'the academic discipline of social psychology is seen as a trivial pseudoscience that expends a great deal of effort describing or providing what we already know' (Furnham, 1983, p. 105).

One way of assessing the utility of explicit psychological studies is to compare their empirical results to those expected or predicted by naive subjects ('intuitive psychologists') on the basis of their intuitive hypothesis. The present article reports an investigation analysing the relationship between implicit psychologists' judgements and explicit empirical results in the field of attitude-behaviour consistency. While it is a well-established commonsense notion that people do not always act in accordance with their attitudes, social scientists have long adhered to the hypothesis of a consistent relationship between attitudes and behaviour-and have been disconfirmed in this belief by a bulk of empirical results ( $c f$. Deutscher, 1973; Mummendey, 1982; Wicker, 1969).

The present analysis points to the question whether the inconclusiveness of empirical evidence on attitude-behaviour consistency corresponds to and is reflected in the intuitive hypothesis of naive subjects.

Our methodological approach is similar to Bem's (1972) method of 'interpersonal simulation'. In a number of studies on the isomorphism of self- and otherperception, Bem demonstrated that observer subjects were highly accurate in predicting the reactions of the actual experimental subjects taking part in studies on self-perception and dissonance reduction. Similarly, our subjects were asked to estimate the degree of attitude-behaviour consistency obtained in a variety of empirical investigations.

In addition to its relevance to research on attitude-behaviour consistency, the present approach is considered paradigmatic for the analysis of implicit psychologies because it provides a direct means of testing the accuracy of behaviour predictions.

Evidence summarized by Crocker (1981) suggests that naive subjects are in fact able to utilize covariation concepts in a fairly accurate way. It is only under this premise that interpersonal simulation may be considered a meaningful methodological device.

\section{METHOD}

From the research literature on attitude-behaviour consistency, twenty empirical studies published between 1955 and 1976 were selected for the present analysis. A list of the studies is presented in Table 1. Variance of the behavioural (or behavioural intention) measures accounted for by the attitudinal variables ranged from 4 per cent to 71 per cent with a mean of 34.5 per cent. Based on the method sections of the original publications, detailed descriptions of the design and procedure of each study were devised and presented to a sample of forty-eight psychology undergraduates. All subjects had completed an introductory statistics course and were familiar with the interpretation of statistical indices. 
Table 1. Selected studies on attitude-behaviour consistency and their coefficients of correspondence

\begin{tabular}{lrlr}
\hline Albrecht et al. (1972) & gamma $=0.71$ & Laing (1970) & gamma $=0.21$ \\
Bellin and Kriesberg (1967) & gamma $=0.37$ & Marais (1967) & $r^{2}=0.06$ \\
Cowdry et al. (1970) & $r^{2}=0.33$ & McGee (1955) & $r^{2}=0.34$ \\
DeFleur and Westie (1958) & gamma $=0.70$ & Pomazal and Jaccard (1976) & $r^{2}=0.48$ \\
DeVries and Ajzen (1971) & $r^{2}=0.50$ & Rokeach and Kliejunas (1972) & $r^{2}=0.04$ \\
Fazio (1969) & $r^{2}=0.17$ & Rosen and Komorita (1971) & $r^{2}=0.35$ \\
Fendrich (1967) & gamma $=0.69$ & Sample and Warland (1973) & $r^{2}=0.08$ \\
Goodmonson and Glaudin (1971) & $r^{2}=0.34$ & Tittle and Hill (1967) & gamma $=0.50$ \\
Green (1972) & $r^{2}=0.19$ & Weigel and Newman (1976) & $r^{2}=0.38$ \\
Kamenetzky et al. (1956) & $r^{2}=0.36$ & Zunich (1962) & $r^{2}=0.10$ \\
\hline
\end{tabular}

Following each description, subjects were asked to estimate the percentage of correspondence obtained by the specific study between the attitudinal and behavioural (or behavioural intention) measures, e.g. 'What is the degree of correspondence (in per cent) between attitudes toward student politics and participation in student political activity?' (Tittle and Hill, 1967). As the correlation coefficient has no direct relationship to everyday concepts of relationships ( $c f$. Crocker, 1981 , p. 279), subjects were asked to predict $r^{2}$ as the percentage of correspondence between attitudes and behaviour. Subjects marked their judgements on a scale ranging from 1 to 100 per cent with decimal subdivisions.

\section{RESULTS AND DISCUSSION}

Kendall tau coefficients were computed to measure the correlation between subjects' covariation judgements and the empirically determined correspondence between attitudes and behaviour in the twenty studies. Kendall's tau is considered more appropriate than the Spearman coefficient as a measure of association between ranks ( $c f$. Hays, 1973, p. 796).

Kendall tau coefficients of correlation between the estimated and obtained results for the individual subjects ranged from -0.230 to 0.480 . The mean Kendall tau between ranks over individuals was $\tau_{\mathrm{i}}=0.099$. The overall Kendall tau coefficient computed across both subjects and items (i.e. studies) reached a score of $\tau_{\mathrm{t}}=0.101$. Neither $\tau_{\mathrm{i}}$ nor $\tau_{\mathrm{t}}$ was statistically significant.

When the Kendall tau coefficients are interpreted in terms of product-moment coefficients, both $\tau_{\mathrm{i}}$ and $\tau_{\mathrm{t}}$ account for approximately 1 per cent of the variance.

It should be recalled that our subjects gave their estimates of attitude-behaviour consistencies on the basis of summarized, though detailed descriptions of the original studies. Considering this limited information, it would appear unwarranted to expect a precise point estimation of the correspondence between attitudes and behaviour. Therefore, both the coefficients obtained in the original studies and the covariation judgements of the subjects were trichotomized to test the weaker hypothesis that subjects' estimates and obtained results are correlated at least within the three broad categories of attitude-behaviour consistency (high, medium, low).

The 'gamma' coefficient of agreement between the original findings and the subjects' estimates computed on the basis of the trichotomized data reached a score of 0.105 , indicating a 10 per cent proportional reduction in variance. Compared to 
the 1 per cent of variance accounted for by the correlation coefficients $\tau_{\mathrm{i}}$ and $\tau_{\mathrm{t}}$, a notable increase in explained variance is achieved by the trichotomization.

Applying this finding to the intuitive psychologists' capacity to predict empirical results, a 'gamma' of 0.105 indicates that the probability of error is reduced by no more than 10 per cent on the basis of the subjects' judgements as opposed to a random assignment of studies (results) to consistency categories.

The present results show the implicit psychologists' difficulties in estimating empirically determined attitude-behaviour consistencies. They are supportive of the claim of scientific psychology to be able to produce non-trivial results, suggesting that other people's reactions in situations where both attitudinal and behavioural variables are involved cannot be adequately accounted for by commonsense psychological knowledge.

It might be argued that subjects were forced to base their predictions on insufficient evidence, being only informed about the independent variables and asked to infer the criterion variable. Recent evidence by Nisbett and Borgida (1975) and Pietromonaco and Nisbett (1982) who provided their subjects with both the hypothesis and results of psychological experiments suggests, however, that intuitive psychologists fail to consider even this complete experimental evidence in predicting the behaviour of target persons in highly similar situations.

Pietromonaco and Nisbett (1982) demonstrate that naive subjects fail to utilize psychological findings that might add to their understanding of another person's behaviour. Subjects were presented an abridged version of the Darley and Bateson (1973) study which demonstrated that a person's willingness to help a victim is critically determined by the degree to which he/she is in a hurry (10 per cent of the people in a hurry versus 63 per cent of the people not in a hurry helped). In a second step, subjects were asked to predict the helping behaviour of stimuluspersons who were either in a hurry or not in similar situations. The results show that the subjects did not attend to the Darley and Bateson findings to predict behaviour: they expected that 59.13 per cent of the stimulus-persons in a hurry and 78.19 per cent of those not in a hurry would help the victim. From their results, Pietromonaco and Nisbett conclude that subjects underutilize a counterintuitive set of findings about a particular helping situation when making predictions about related situations, thus suggesting the insensitivity of commonsense hypotheses to scientific psychological evidence.

Another reason for the subject's failure to predict attitude-behaviour consistencies could be seen in the methodology of the present study which can be characterized in Mixon's (1972) terms as a kind of nonactive role-playing. Subjects were asked to make judgements about others' behaviour on the basis of a description of the experimental situation necessarily restricted in terms of realism and spontaneity.

Mixon (1972) suggests that experimental results are more likely to be reproduced through active role-playing where subjects are placed into the experimental setting and asked to behave as if they were naive participants. Applying this argument to the present study, subjects' estimates of attitude-behaviour relations could possibly be facilitated by introducing active role-playing, i.e. by presenting the original materials and asking subjects to respond to them from the perspective of a prototypical member of the original sample.

As to the present results, however, it may be a comforting thought to the implicit 
psychologists that they are no less successful in predicting empirical results on the basis of intuitive theories than explicit psychologists are in predicting behaviour on the basis of attitudes. As Wicker's (1969) review of 46 studies on attitudebehaviour consistency shows, the average amount of behavioural variance accounted for by attitudinal variables lies at about 10 per cent.

Even if more recent studies are considered using more specific attitudinal measures to predict behaviour-as suggested in Fishbein and Ajzen's (1975) concept of 'correspondence'-support for the consistency hypothesis between attitudes and behaviour remains weak. Fazio and Zanna (1978) postulated that attitudebehaviour consistency should increase as a function of prior experience with the attitude object. While their results were in the predicted direction-attitudebehaviour correlations being 0.419 and 0.360 , and -0.033 for subjects who had high, moderate and low direct experience with the attitude object-even in the high experience group no more than 18 per cent of the behavioural variance could be accounted for by the attitudinal predictors ( $c f$. also Fazio and Zanna, 1981).

Jaccard, King and Pomazal (1977) varied the specificity of the attitude measures in three different domains: birth control, church attendance and blood donation. The most specific attitude measures, assessing subjects' attitudes toward 'using birth control pills', 'attending church this Sunday', and 'donating blood at the upcoming blood drive', explained between 18 per cent and 42 per cent of the behavioural variance. Apart from the conceptual problem to distinguish this highly specific definition of attitudes from the behavioural intention variable, the predictive power of the attitude concept is still not very impressive.

In view of the obvious difficulties in predicting behaviour successfully on the basis of attitudes, the focus of research has shifted towards the elaboration of behaviour prediction models specifying a number of additional behavioural predictors and moderators between attitudes and behaviour like, e.g. subjective norms (Ajzen and Fishbein, 1980), social pressure (Andrews and Kandel, 1979), or selfmonitoring (Snyder, 1982).

Recent empirical evidence suggests that these additional variables lead to an improvement of behaviour prediction in many instances. A comprehensive account of current developments in attitude-behaviour research is presented by Zanna, Higgins and Herman (1982).

It might be fruitful to apply the methodology of the present study to some of these more recent investigations by asking naive subjects to predict their results. If more complex models of behaviour prediction like, e.g. Ajzen and Fishbein's (1980) 'theory of reasoned action' are employed, subjects can be asked to estimate the amount of variance accounted for by each of the components specified by the model.

The predictive validity of these estimates will, however, be critically dependent on the 'diagnosticity' of the evidence (Trope and Bassok, 1982), i.e. on the extent to which the various aspects of the reported investigations can be unequivocally related to each other by the naive judges. In addition, the predictor variables as well as the criterion have to be controlled in terms of their accessibility and relevance (Zanna and Fazio, 1982) for both the subjects of the original studies and the subjects judging from the implicit psychologist perspective. 


\section{REFERENCES}

(Studies not mentioned in the text but referred to in Table 1 are marked with an asterisk)

Ajzen, I. and Fishbein, M. (1980). Understanding Attitudes and Predicting Social Behavior, Prentice Hall, Englewood Cliffs, N.J.

*Albrecht, R. J., DeFleur, M. L. and Warner, L. G. (1972). 'Attitude-behavior relationships. A reexamination of the postulate of contingent consistency', Pacific Sociological Review, 15: 149-168.

Andrews, K. H. and Kandel, D. B. (1979). 'Attitude and behavior: A specification of the contingent consistency hypothesis', American Sociological Review, 44: 298-310.

${ }^{*}$ Bellin, S. S. and Kriesberg, L. (1967). 'Relationship among attitudes circumstances and behavior', Sociology and Social Research, 51: 453-469.

Bem, D. J. (1972). 'Self-perception theory'. In: Berkowitz, L. (Ed.) Advances in Experimental Social Psychology, Vol. 6, Academic Press, New York.

*Cowdry, W., Keniston, K. and Cabin, S. (1970). 'The war and military obligation: Private attitudes and public opinions', Journal of Personality, 38: 525-549.

Crocker, J. (1981). 'Judgment of covariation by social perceivers', Psychological Bulletin, 90: $272-292$.

Darley, J. M. and Bateson, C. D. (1973). "From Jerusalem to Jericho": A study of situational and dispositional variables in helping behavior', Journal of Personality and Social Psychology, 27: 100-108.

* DeFleur, M. L. and Westie, F. R. (1958). 'Verbal attitudes and overt acts', American Sociological Review, 23: 667-673.

Deutscher, I. (Ed.) (1973). What We Say/What We Do. Sentiments and Acts. Scott, Foresman, Glenview, Ill:

*DeVries, D. L. and Ajzen, I. (1971). 'The relationship of attitudes and normative beliefs to cheating in college', Journal of Social Psychology, 27: 199-207.

*Fazio, A. F. (1969). 'Verbal and overt behavioral assessment of a specific fear', Journal of Consulting and Clinical Psychology, 33: 705-709.

Fazio, R. H. and Zanna, M. P. (1978). 'Attitudinal qualities relating to the strength of the attitude-behavior relationship', Journal of Experimental Social Psychology, 14: 398-408.

Fazio, R. H. and Zanna, M. P. (1981). 'Direct experience and attitude-behaviour consistency', In: Berkowitz, L. (Ed.) Advances in Experimental Social Psychology, Vol. 14, Academic Press, New York.

${ }^{*}$ Fendrich, J. A. (1967). 'A study of association among verbal attitudes, commitment, and overt behavior experimental situations ...' Social Forces, 45: 347-355.

Fishbein, M. and Ajzen, I. (1975). Belief, Attitude, Intention, and Behavior, AddisonWesley, Reading, Mass.

Furnham, A. and Henderson, M. (1983). 'Lay theories of delinquency', European Journal of Social Psychology, 12: 107-120.

Furnham, A. (1983). 'Social psychology as common sense', Bulletin of the British Psychological Society, 36: 105-109.

* Goodmonson, C. and Glaudin, V. (1971). 'The relationship of commitment-free behavior and commitment: A study toward organ transplantation', Journal of Social Issues, 27: $171-183$.

Green, J. A. (1972). 'Attitudinal and situational determinants of intended behavior toward blacks', Journal of Personality and Social Psychology, 22: 13-17.

Hays, W. L. (1973). Statistics for the Social Sciences, Holt, Rinehart \& Winston, London.

Jaccard, J., King, G. and Pomazal, R. (1977). 'Attitudes and behavior: An analysis of specificity of attitudinal predictors', Human Relations, 30: 817-824.

*Kamenetzky, J., Burgess, G. and Rowan, T. (1956). 'The relative effectiveness of four assessment techniques in predicting a criterion', Educational and Psychological Measurement, 16: 187-194.

* Laing, J. E. (1970). 'The relationship between attitude and behavior: The case of family planning.' In: Bogue, D. J. (Ed.) Further Sociological Contributions to Family Planning Research, Community and Family Study Center, University of Chicago, Chicago. 
* Marais (1967). 'Evaluation of the semantic differential as an instrument for measurement of attitudes', Psychological Reports, 21: 591-592.

* McGee, H. M. (1955). 'Measurement of authoritarianism and its relation to teachers' classroom behavior', Genetic Psychology Monographs, 52: 89-146.

Mixon, D. (1972). 'Instead of deception', Journal for the Theory of Social Behaviour, 2: $145-178$.

Mummendey, H. D. (1982). Attitudes and Behavior-A Review of the German Literature, Bielefelder Arbeiten zur Sozialpsychologie, No. 93.

Nisbett, R. and Borgida, E. (1975). 'Attribution and the psychology of prediction', Journal of Personality and Social Psychology, 32: 932-943.

Pietromonaco, P. R. and Nisbett, R. E. (1982). 'Swimming upstream against the fundamental attribution error: Subjects' weak generalizations from the Darley and Bateson study', Social Behavior and Personality, 10: 1-4.

* Pomazal, R. J. and Jaccard, J. J. (1976). 'An informational approach to altruistic behavior', Journal of Personality and Social Psychology, 33: 317-326.

* Rokeach, M. and Kliejunas, P. (1972). 'Behavior as a function of attitude-toward-object and attitude-toward-situation', Journal of Personality and Social Psychology, 22: 194-201.

* Rosen, B. and Komorita, S. S. (1971). 'Attitudes and action. The effects of behavioral intent and perceived effectiveness of acts', Journal of Personality, 39: 189-203.

*Sample, J. and Warland, R. (1973). 'Attitude and prediction of behavior', Social Forces, 51: 292-304.

Schneewind, K. A. (1982). Persönlichkeitstheorien I: Alltagspsychologische und mechanistische Ansätze, Wissenschaftliche Buchgesellschaft, Darmstadt.

Semin, G. R., Rosch, E., Krolage, J. and Chassein, J. (1981). 'Alltagswissen als implizite Basis für "wissenschaftliche" Persönlichkeitstheorien: Eine sozialpsychologische Untersuchung', Zeitschrift für Sozialpsychologie, 12: 233-242.

Sjöberg, L. (1982a). 'Logical versus psychological necessity: A discussion of the role of common sense in psychological theory', Scandinavian Journal of Psychology, 23: 65-78.

Sjöberg, L. (1982b). 'Common sense and psychological phenomena: A reply to Smedslund', Scandinavian Journal of Psychology, 23: 83-85.

Smedslund, J. (1982). 'Common sense as psychosocial reality', Scandinavian Journal of Psychology, 23: 79-82.

Snyder, M. (1982). 'When believing means doing: Creating links between attitudes and behavior'. In: Zanna, M. P., Higgins, E. T. and Herman, C. P. (Eds) Consistency in Social Behavior: The Ontario Symposium, Vol. 2, L. Erlbaum, Hillsdale, N.J.

Tittle, C. and Hill, R. J. (1967). 'The accuracy of self-reported data and prediction of political activity', Public Opinion Quarterly, 31: 103-106.

Trope, Y. and Bassok, M. (1982). 'Confirmatory and diagnosing strategies in social information gathering', Journal of Personality and Social Psychology, 43: 22-34.

Wegner, D. M. and Vallacher, R. R. (1977). Implicit Psychology-An Introduction to Social Cognition, Oxford University Press, New York.

${ }^{*}$ Weigel, R. H. and Newman, L. S. (1976). 'Increasing attitude-behavior correspondence by broadening the scope of the behavioral measure', Journal of Personality and Social Psychology, 33: 793-802.

Wicker, A. W. (1969). 'Attitudes vs. actions: The relationship of verbal and overt behavioral responses to attitude objects', Journal of Social Issues, 25: 41-78.

Wish, M. and Kaplan, S. J. (1977). 'Toward an implicit theory of interpersonal communication', Sociometry, 40: 234-246.

Zanna, M. P. and Fazio, R. H. (1982). 'The attitude-behavior relation: Moving toward a third generation of research'. In: Zanna, M. P., Higgins, E. T. and Herman, C. P. (Eds) Consistency in Social Behavior: The Ontario Symposium, Vol. 2, L. Erlbaum, Hillsdale, N.J.

Zanna, M. P., Higgins, E. T. and Herman, C. P. (Eds) (1982). Consistency in Social Behavior. The Ontario Symposium, Vol. 2, L. Erlbaum, Hillsdale, N.J.

*Zunich, M. (1962). 'Relationship between maternal behavior and attitudes toward children', Journal of Genetic Psychology, 100: 155-165. 


\section{RÉSUMÉ}

Pour examiner la relation entre les théories psychologiques implicites et les résultats empiriques explicites, des résumés de 20 études publiées sur la consistance attitude-comportement ont été présentés à un échantillon de 48 étudiants de psychologie. Les sujets devaient estimer le degré de concordance obtenu dans chaque étude entre les attitudes et le comportement. Les corrélations entre les jugements de covariation des sujets et les concordances obtenues empiriquement furent minimes et non significatives. Les résultats sont discutés à la lumière des plus récentes recherches dans le domaine des relations entre attitudes et comportement.

\section{ZUSAMMENFASSUNG}

Um die Beziehung zwischen impliziten psychologischen Hypothesen und expliziten empirischen Befunden zu untersuchen, wurden Kurzberichte von zwanzig veröffentlichten Studien zur Konsistenz von Verhalten und Einstellung einer Stichprobe von 48 Psychologiestudenten vorgelegt. Die Vpn waren gehalten den Grad der Uebereinstimmung von Verhalten und Einstellung abzuschätzen, der in den verschiedenen Studien zum Ausdruck kam. Die Korrelation zwischen der Konkordanzbeurteilung und der empirisch gefundenen Konkordanz fiel minimal aus und war nicht signifikant. Die Ergebnisse werden diskutiert im Lichte neuester Untersuchungen, in denen die Beziehung Verhalten/Einstellung im Mittelpunkt steht. 